\title{
In Response: Maintaining Professional Relationships in an Interdisciplinary Setting: Strategies for Navigating Non-behavioral Treatment Recommendations for Individuals with Autism
}

\author{
James K. Luiselli
}

Published online: 6 February 2015

(C) Association for Behavior Analysis International 2015

The topic of this article is particularly relevant for boardcertified behavior analysts (BCBAs) working in interdisciplinary settings. Certainly, it is common for BCBAs to be confronted with "non-behavioral treatment recommendations" from interdisciplinary team colleagues. In most cases, even highly experienced behavioral professionals are challenged by this situation. Specifically, the decision-making that Brodhead proposes informs BCBAs about maintaining professional relationships within interdisciplinary settings for individuals with ASD. The model also appears to be applicable with other populations as well.

I was pleased to see that Brodhead carefully linked his presentation and recommendations to the Guidelines for reasonable conduct for behavior analysts promulgated by the Behavior Analyst Certification Board (BACB). Additionally, he acknowledged that the decision-making model represents his professional values, and as such, "it is likely that there are other courses of action BCBAs may take when faced with a non-behavioral treatment." Notwithstanding his disclaimer, the article contains practical suggestions that most BCBAs should be able to implement in a variety of educational and treatment settings.

In presenting his decision-making model, Brodhead referred several times to the roles and responsibilities of members on an interdisciplinary team. I note that some BCBAs may have limited involvement with such teams while, in other situations, they may fulfill a larger role and have more expectations. Accordingly, following the decision-making model

J. K. Luiselli $(\bowtie)$

Clinical Solutions, Inc., and North East Educational and Developmental Support Center, Tewksbury, MA, USA

e-mail: jluiselli@needsctr.org would seem to be dictated, in part, on the defined responsibilities assigned to the participating BCBA. My point here is (a) to underscore the need of having clear role definitions on an interdisciplinary team and (b) to suggest that different levels of involvement and responsibility will determine a BCBA's ability to implement the decision-making model.

I also think that social validity assessment should be a component on the decision-making model. That is, how do other members of an interdisciplinary team judge the performance and contributions of BCBAs? To illustrate, one can create a simple questionnaire that asks interdisciplinary team members to rate their satisfaction with and acceptability of the input from and interactions with a BCBA. As well, a questionnaire can sample team member's opinions about other attributes of a BCBA such as speaking respectfully, listening attentively, resolving questions, and the like. In effect, BCBAs should seek feedback about their performance among colleagues - in this case, doing so seems particularly relevant when applying the decision-making model.

Finally, there is the matter of training and supervising BCBAs in the skills necessary to conduct behavioral consultation in general and specifically with interdisciplinary colleagues. The BACB requires comprehensive training of behavior analysts for conducting supervision and, additionally, annual continuing education devoted to supervisory practices. The BACB training guidelines, in fact, address many of the points that Brodhead presents, pertaining to professional relationships, interacting with colleagues, and delivering feedback. I suspect that successful implementation of this decision-making model by BCBAs will depend on them being properly trained and monitored as, and by, a supervisor. 